\title{
HELMINTH ASSOCIATIONS IN WHITE-TOOTHED SHREWS CROCIDURA RUSSULA (INSECTIVORA: SORICIDAE) FROM THE ALBUFERA NATURAL PARK, SPAIN
}

\author{
Enrique Portolés, Pedro Granel, J. Guillermo Esteban, and Jacques Cabaret ${ }^{\star} \dagger$ \\ Departamento de Parasitología, Facultad de Farmacia, Universidad de Valencia, Avenida Vicente Andrés Estellés s/n, 46100 Burjassot, \\ Valencia, Spain. e-mail: cabaret@tours.inra.fr
}

\begin{abstract}
The helminths of 218 white-toothed shrews from 29 sites in 2 biotopes in the Albufera Natural Park (Valencia, Spain) were examined from July 1990 to August 1991. An association analysis of helminths occurring at a prevalence of more than $4 \%$ was carried out for 4 species of cestodes located in the intestine (Hymenolepis pistillum, H. scalaris, H. tiara, and Pseudhymenolepis redonica) and 3 species of nematodes (Pseudophysaloptera sp. located in the stomach, Stammerinema rhopocephala larvae in the intestine and abdominal cavity, and Porrocaecum sp. in the thoracic and abdominal cavities). Bivariate (species pairs) versus multivariate analyses (associations within the entire set of species) were performed of presence-absence and of quantitative records (influence of intensity on associations). The associations were evaluated with respect to the sex and age of the host and to the sampling date and sites. The host and environment played a limited role, and the major determinant of species assemblage was phylogenetic. Positive associations were found among both the cestodes and the nematodes, whereas negative associations were found between cestodes and nematodes. The type of life cycle was probably the second greatest determinant of species associations. Nematodes using shrews as a paratenic host or as their definitive host were both positively associated.
\end{abstract}

The helminths of the white-toothed shrew have been studied in several parts of Europe, see the review of Vaucher (1971) of European shrews, that of Joyeux and Baer $(1936,1937)$ in Switzerland, and that of Quentin (1986) in France. In Spain, the helminths infesting these shrews (Mas-Coma and Gallego, 1977; Mas-Coma, 1977, Portolés et al., 1996) have been studied less intensively than those found in other rodents (Mas-Coma and Gallego, 1975; Mas-Coma and Feliu, 1977; Feliu et al., 1997). The Spanish helminth fauna of Crocidura russula (Hermann, 1780) identified to date comprises 49 species, i.e., 14, 13,21 , and 1 species of trematodes, cestodes, nematodes, and acanthocephalans, respectively. Thus, the helminth fauna is species rich and is composed of species with different life cycles, but the degree of infestation is low. The helminth fauna in the Albufera Natural Park (on the eastern coast of Spain) compared with other sites studied is characterized by the presence of a single species of trematode and a larger number of nematodes and cestodes (Portoles et al., 1996). The limited number of trematodes is paralleled by the low prevalence of trematode infections in intermediate snail hosts (Toledo et al., 1998).

The assemblage of species may depend on a variety of factors in nature, such as climate (Haukisalmi and Henttonen, 1994 in shrews from Finland), introduction or loss of species as a result of host movements, individual-, age-, or sex-induced host resistance, host feeding habits, and interactions between species. The present study was undertaken entirely within the Albufera Natural Park, therefore climatic conditions were uniform. Slight local variations in the moisture level may affect the presence of shrews because they are found primarily in moist zones (Faus, 1990). Accordingly, sampling in several zones is required to encompass local environmental variability. White-toothed shrews feed on live or, less frequently, dead invertebrates, which are intermediate hosts for cestodes; these shrews also constitute prey for birds and act as paratenic hosts for several nematodes.

Received 13 August 2001; revised 10 November 2003; accepted 10 November 2003.

* Equipe ecologie et génétique des parasites, Unité BioAgresseurs, Santé, Environnement, INRA, 37380 Nouzilly, France.

$\dagger$ To whom correspondence should be addressed.
Shrews are monogamous, and their movements are limited. Each litter comprises 3-4 progeny, and several generations are usually produced during the breeding period (spring to the end of summer). Postnatal dispersal is low; most juveniles settle within their natal territory or 1 immediately adjacent, and dispersal is restricted to the first litter of juveniles weaned in May (Favre et al., 1997). The movements of young shrews are subsequently also limited. Accordingly, the introduction or loss of helminth species as a result of host movements within a small area is probably negligible. Individual-, sex-, or age-related resistance has not been evaluated in shrews, and this must be done before any study of helminth associations can be undertaken. Interaction between species has been considered to be a major determinant of the host-parasite community structure. Communities display very different organizations: thus out of 50 studied assemblages of fish ectoparasites, ectoparasite species were distributed randomly within 20 , whereas they were not distributed randomly in the other 30 (Poulin and Guegan, 2000). Community organization (Holmes and Price, 1986) has been classified as isolationist (a few species independently distributed and low infestation rates) or interactive (interaction plays a key role in determining the structure of the community). Pence (1990) further described the criteria for predicting an isolationist community as a low probability of colonizing the host, a direct life cycle, unsaturated niche use, low species richness, and a small number of high-density species. Some of the characteristics of the helminth community of C. russula indicate an isolationist community (direct life cycle, small number of high-density species), whereas others increase the possibility of an interactive community (indirect life cycle, high mean species diversity).

The intensity of associations determined under natural conditions may correspond to a mutualistic effect but may also be caused by similarities of life cycle. This means that helminth species associations in natural infestations do not necessarily reflect interactions between parasite species. Associations between helminth species can be estimated pairwise using indices: Pearson's coefficient of correlation, (Barger, 1984) or Spearman's rank correlation, when quantitative data are available, or indices such as the Sokal-Michener, Jaccard, or Dice indices, when only presence-absence data are available. Multivariate 
TABLE I. List and characteristics of the helminths recovered in 218 Crocidura russula during a 1-yr sampling period (1990-1991) in 2 biotopes of Dehesa zone in the Albufera Natural Park of Valencia, Spain.*

\begin{tabular}{|c|c|c|c|c|c|}
\hline Helminth & Prevalence & $\begin{array}{c}\text { No. of worms } \\
\text { per host } \\
\text { (abundance } \pm \text { SD) }\end{array}$ & $\begin{array}{l}\text { Parasite } \\
\text { location }\end{array}$ & $\begin{array}{l}\text { Host } \\
\text { range on } \\
\text { the site } \dagger\end{array}$ & Life cycle \\
\hline Brachylaima sp. & 1.8 & $0.03 \pm 0.2$ & Intestine & $\mathrm{Cr}, \mathrm{Ms}, \mathrm{Rr}, \mathrm{As}$ & Indirect \\
\hline \multicolumn{6}{|l|}{ Cestoda } \\
\hline Hymenolepis pistillum (Hp) & 23.8 & $42.0 \pm 192$ & Intestine & $\mathrm{Cr}$ & $\begin{array}{l}\text { Indirect (insects as intermedi- } \\
\text { ary hosts) }\end{array}$ \\
\hline Hymenolepis scalaris (Hs) & 12.8 & $0.2 \pm 0.8$ & Intestine & $\mathrm{Cr}$ & $\begin{array}{l}\text { Indirect (insects as intermedi- } \\
\text { ary hosts) }\end{array}$ \\
\hline Hymenolepis tiara $(\mathrm{Ht})$ & 22.5 & $0.9 \pm 3.0$ & Intestine & $\mathrm{Cr}$ & $\begin{array}{l}\text { Indirect (insects as intermedi- } \\
\text { ary hosts) }\end{array}$ \\
\hline Hymenolepis spp. & 11.0 & $0.2 \pm 1.0$ & Intestine & - & $\begin{array}{l}\text { Indirect (insects as intermedi- } \\
\text { ary hosts) }\end{array}$ \\
\hline Pseudhymenolepis redonica $(\operatorname{Pr})$ & 32.6 & $19.1 \pm 119$ & Intestine & $\mathrm{Cr}$ & $\begin{array}{l}\text { Indirect (insects as intermedi- } \\
\text { ary hosts) }\end{array}$ \\
\hline Calodium soricicola & 1.4 & $0.01 \pm 0.1$ & Liver & $\mathrm{Cr}$ & Direct \\
\hline Aonchotheca europaea & 2.7 & $0.10 \pm 0.9$ & Stomach & $\mathrm{Cr}$ & Indirect? \\
\hline Parastrongyloides winchesi & 3.2 & $0.06 \pm 0.3$ & Intestine & $\mathrm{Cr}$ & Direct \\
\hline Paracrenosoma combesi & 0.5 & $0.00 \pm 0.07$ & Lung & $\mathrm{Cr}$ & Indirect \\
\hline Longistriata sp. & 1.4 & $0.01 \pm 0.1$ & Intestine & $\mathrm{Cr}$ & Direct \\
\hline Porrocaecum sp. (larvae) (P) & 35.8 & $1.5 \pm 3.3$ & $\begin{array}{l}\text { Thoracic and ab- } \\
\text { dominal cavities }\end{array}$ & $\mathrm{Cr}, \mathrm{Rr}$, As & $\begin{array}{l}\text { Indirect-paratenic host (birds } \\
\text { definitive hosts) }\end{array}$ \\
\hline Pseudophysaloptera sp. (Pse) & 4.1 & $0.1 \pm 0.6$ & Stomach & $\mathrm{Cr}$ & $\begin{array}{l}\text { Indirect (insects as intermedi- } \\
\text { ary hosts) }\end{array}$ \\
\hline Gongylonema sp. aff. Soricis & 0.9 & $0.01 \pm 0.1$ & Esophagus & $\mathrm{Cr}$ & $\begin{array}{l}\text { Indirect (Blattidae as interme- } \\
\text { diary hosts) }\end{array}$ \\
\hline $\begin{array}{l}\text { Stammerinema rhopalocephala } \\
\quad \text { (larvae) }(\mathrm{Sr})\end{array}$ & 24.8 & $1.9 \pm 10.3$ & $\begin{array}{l}\text { Intestine and ab- } \\
\text { dominal cavity }\end{array}$ & $\mathrm{Cr}$ & $\begin{array}{l}\text { Indirect-paratenic host (birds } \\
\text { as definitive hosts) }\end{array}$ \\
\hline
\end{tabular}

* Unpublished data from E. Portolés.

$\dagger \mathrm{Cr}$, Crocidura russula; Ms: Mus spretus, Rr: Rattus rattus, As: Apodemus sylvaticus.

estimates are also available (Cabaret and Hoste, 1998). Positive associations are sometimes linked to the structure of the data (joint presences or absences in hosts) rather than interspecific facilitation (Lotz and Font, 1994), indicating that statistical associations between species must be carefully interpreted in terms of interactions.

In the present study, the helminth associations of crocidurine shrews are described in the light of life-cycle type, biotope, host characteristics, and the prevalence and intensity of infestation, using either presence-absence or quantitative infection data analyzed using bivariate or multivariate procedures. Associations are also evaluated in relation to taxonomic similarities (linked to life cycles) and ecological similarities (in the sense of a "guild" as defined by Root, 1967).

\section{MATERIALS AND METHODS}

\section{Host collections}

White-toothed shrews were studied in the 21,000-ha Albufera Natural Park (10 km to the south of the city of Valencia, Spain) from July 1990 to August 1991. This park is 1 of the few large wetlands areas remaining in Europe and constitutes a way station for many species of migratory birds, the definitive hosts of parasites that use the shrews as their paratenic hosts. The area studied in the Park (Dehesa) is an 871-ha littoral sandbar separating the inland lake from the Mediterranean Sea. Two sites were investigated; each enclosed naturally by fireguards and small roads and separated by a distance of $2 \mathrm{~km}$ and a $57-\mathrm{m}$ wide canal, to minimize the exchange of rodents or insectivores from 1 biotope to another. The B1 site, $342,536 \mathrm{~m}^{2}$ (nearer to the rice paddies, divided into 13 nearly equal sampling areas covering the entire area), was covered with matorrals (Phillyreo angustifoliae and Rhamnus angustifoliae) with or without myrtle (Myrtus communis); some smaller areas were covered with Teucrium belionis and Imperata cylindrica or replanted with Eucalyptus sp. The B2 site, 354,136 m² (nearer to the Albufera Lake and more visited by birds; 16 sampling areas), was covered with similar matorrals. Some of the areas were covered with sedge (Carex extensae), reed (Juncus maritimum), Phragmites isiaca, or I. cylindrinca or had been replanted with Eucalyptus sp. or Pinus sp. The average surface area of a sampling area was approximately $23,000 \mathrm{~m}^{2}$, and the maximum distance between areas was $955 \mathrm{~m}$ within each biotope (B1 or B2). In each biotope, shrews were trapped every $2 \mathrm{wk}$. There were 25 sampling periods. At each sampling period, 2 areas were usually inspected using 110 Shermann traps. Each of the 29 sampling areas was sampled from 1 to 3 times during the study.

\section{Parasitological methods}

At necropsy, the following organs were examined using a stereomicroscope to identify the parasites: esophagus, stomach, intestines, liver, spleen, lungs, urinary bladder, heart, and abdominal and thoracic cavities. Before identification, nematodes and cestodes were fixed and preserved in $70 \%$ alcohol, and trematodes, first, in Bouin solution and then in $70 \%$ alcohol. Final preparations of platyhelminths were mounted in toto in Canada balsam after staining (Grenacher boric carmine for trem- 


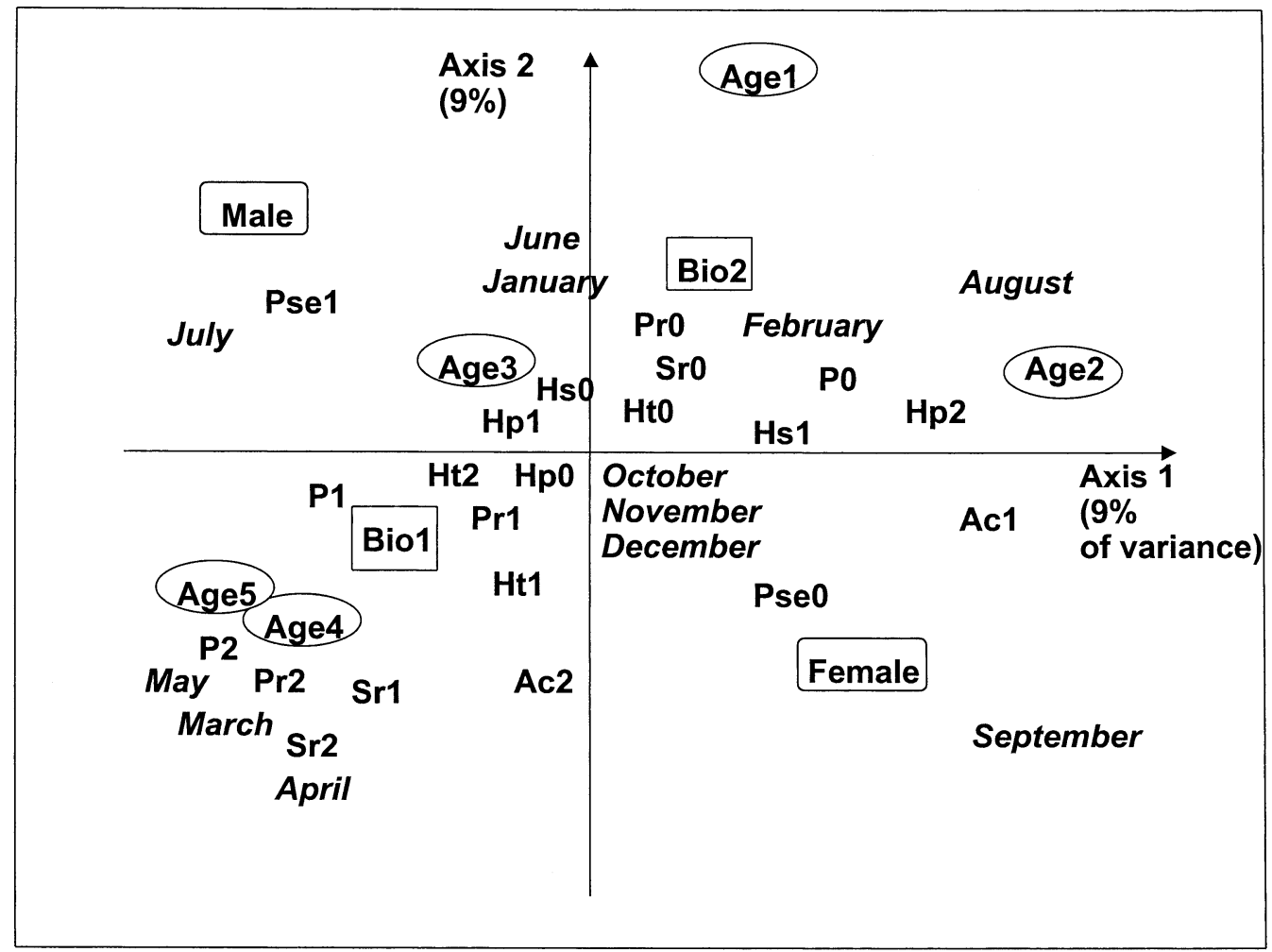

FIGURE 1. Environment- and host-related factors in helminth infection. The numbers in parentheses represent numbers of worms. Codes: Bio 1 and Bio 2: biotopes 1 and 2, respectively; Age 1 (0-6 wk), Age 2 (6-14 wk), Age 3 (3.5-9 mo), Age 4 (9-14 mo), Age 5 (14-18 mo); Ac1 and Ac2: nonpregnant and pregnant females, respectively; Hp (Hymenolepis pistillum): Hp0 (not infected), Hp1 (1-14), Hp2 (15-2,092); Hs (H. scalaris): Hs0 (0), Hs1 (1-9); Ht (H. tiara): Ht0 (0), Ht1 (1-2) and Ht2 (3-29); Pr (Pseudhymenolepis redonica): Pr0 (0), Pr1 (1-5), Pr2 (61,525); P (Porrocaecum sp.): P0 (0), P1 (1-2) and P3 (3-21); Pse (Pseudophysaloptera sp.): Pse0 (not infected) and Pse1 (1-7); Sr (Stammerinema rhopalocephala): $\mathrm{Sr} 0(0), \operatorname{Sr} 1(1-2)$ and $\mathrm{Sr} 2(3-140)$.

atodes or chlorhydric carmine hydrochloride for cestodes). Nematodes were studied as wet mounts, first in water and then in lactophenol. The numbers of parasites (nematodes and trematodes) or scolices (cestodes, except for Pseudhymenolepis redonica) were enumerated.

\section{Statistical methods}

The indices of similarity (see L. Legendre and P. Legendre, 1979) are numerous. We used 1 that includes double absences (Sokal and Michener, 1958), and another that excluded double absences; the former gives equal weight to each data pair (Jaccard, 1908), and the latter gives extra weight to the cooccurrence of 2 species within a host (Dice, 1945). A distance measure based on 1 - coefficient of correlation was used for quantitative data; values ranged from 0 (full positive association) to 2 (full negative association). Correspondence analyses were performed with STAT-ITCF software (1988), using simple (helminth data) or multiple (helminth, environment, and host) correspondence analyses (CAs) The Euclidean distances between species (dCApa and dCAq, for presence-absence data and qualitative data fell into 3 classes of data, respectively) were derived from CAs in a manner similar to that described in Cabaret and Hoste (1998) for principal component analyses. They were scaled so that their absolute values could be compared. Principal component analysis on standardized data was also performed using the same software. In the present study, CAs (able to handle categorical data) were preferred to principal component analyses (used for quantitative data) because we could compare associations on the basis of presence-absence or parasite numbers arranged into classes using the same type of analysis. The Mantel test (1967) was used to compare distance matrices established by several indices of association. One-way analyses of variance were standard.

\section{RESULTS}

\section{Insectivores and rodents collected}

Crocidura russula accounted for $38.3 \%$ of the total insectivores; the rodents included (569), Apodemus sylvaticus $44.1 \%$, Rattus rattus $10.0 \%$, and Mus spretus $7.6 \%$. The M. spretus was relatively more frequent at the B1 site, whereas all the other species were recorded more often at the B2 site. The average weight of the $C$. russula caught was $8.8 \mathrm{~g}(\mathrm{SD}=3.4)$, and the mean age according to I. E. Vesmanis and A. Vesmanis (1979) was 3.5-9 mo.

\section{Characteristics of infestation}

One species of trematode, 4 species of cestode, and 10 species of nematode were found (Table I). Practically all these helminth species are specific for $C$. russula, and the majority had indirect life cycles. The prevalence of most of the species found was very low, and only those for which the prevalence was more than $4 \%$ were taken into consideration. The abundance was low in most cases, except for Hymenolepis pistillum and $P$. redonica. For these 2 parasites, most of the worms were concentrated in a few hosts, as shown by the large variancemean ratio. 
TABLE II. Pairwise associations between parasite species infesting shrews: distances based on dCApa for the presence-absence or ( 1 - r) and (dCAq) of abundance data divided into 3 classes and their similarities (Sokal-Michener, Jaccard, or Dice indices).

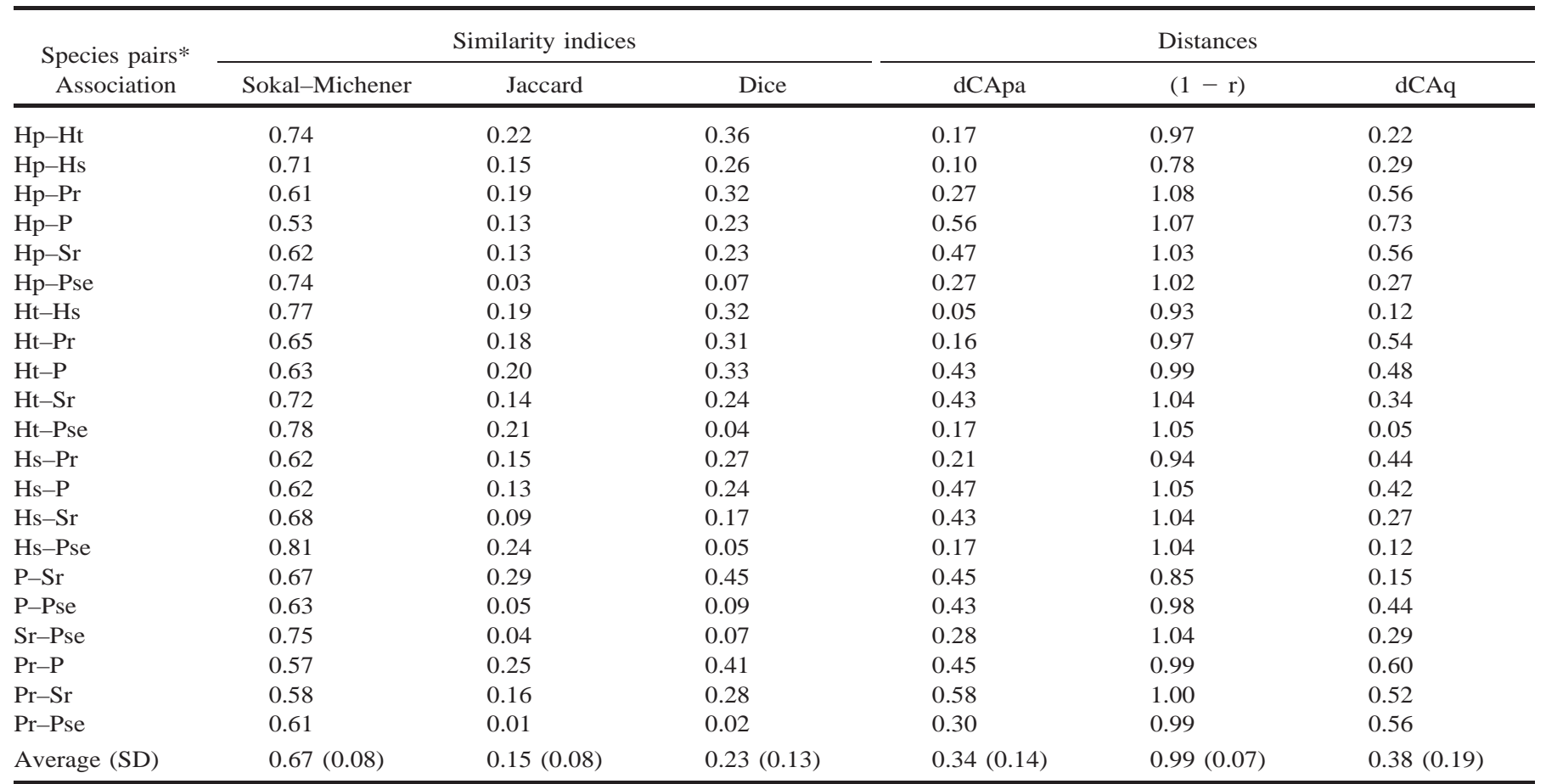

* Cestodes: Hp (Hymenolepis pistillum), Hs (H. scalaris), Ht (H. tiara), and Pr (Pseudhymenolepis redonica). Nematodes: P (Porrocaecum sp.), Pse (Pseudophysaloptera sp.) and $\mathrm{Sr}$ (Stammerinema rhopalocephala).

\section{Species proportions in relation to host and environment}

One-way analysis of variance (ANOVA) (biotope being the studied factor) showed that the helminth fauna (proportion of species, arc sine transformed) was the same for biotopes Bio1 and $\operatorname{Bio} 2(P=0.20)$. The age of the shrew was a major factor in the log-transformed values of species abundance $(H$. pistillum, $P<0.001$, higher values at age $2 ; H$. tiara, $P=0.06$, higher values at age 4 and 5; Porrocaecum sp., $P<0.001$, higher values at age 4 and 5). In itself, season was not an important source of variation for the proportion of species but was related to the age $(P=0.01)$ or weight $(P<0.01)$ of the hosts. The sex of the host shrews was not linked to any significant variation of helminth infections, except in the case of Pseudophysaloptera sp.; males were more heavily infected with this species than females $(P<0.01)$. The results from multiple CAs are shown in Fig. 1. Environmental and host descriptors were used to construct the analysis, and the parasitological data were used as supplementary variables (they were identified post hoc on the graph derived from the environment-host data). The variables that were located in the same part of the graph were associated positively (see age 4 and age 5 and the March, April, May samplings), whereas those that were located in widely separated parts of the graph were associated negatively (male vs. female); variables located at $90^{\circ}$ sites were independent (Bio2 and female for example). The older shrews (age category 4 and 5) in March, April, and May clearly harbored a heavier load of $P$. redonica, Porrocaecum sp. larvae, and Stammerinema rhopalocephala, whereas younger shrews were more heavily infested with $H$. pistillum. Males were infested more intensely with Pseudophysaloptera sp. than females. However, the asso- ciation between environment and species was low because only $18 \%$ of variance was recorded on the first 2 axes. At the scale we investigated parasites of $C$. russula, the associations of species may also be determined by other nonenvironmental factors. The results from ANOVA and CAs are somewhat similar because neither indicates any strong relationships between host environment and species association.

\section{Bivariate versus multivariate analysis of presence- absence data: interrelations in species associations}

The matrix of distances between Sokal-Michener, Jaccard, and Dice bivariate indices (Table II) were compared using a Mantel test. They were not significantly correlated. Conversely, the distance matrix derived from $\mathrm{CA}$ on presence-absence data (dCApa) was related to Sokal-Michener distances $(P=0.03)$. The univariate Sokal-Michener and dCApa indices were calculated including joint absences, which may explain their similarity. The fact that the multivariate (all species associations) and 1 univariate index (paired species) are closely correlated, indicates that the presence of any particular species of helminth is probably not related to the presence or absence of any other helminth species.

\section{Multivariate analysis of categorical versus quantitative data: species abundance and associations}

The associations were related to taxonomic groups. The cestodes were usually positively associated, and the nematodes were also positively associated (Fig. 2A-C). This was found for all analyses. The mean distances gained from dCApa and dCAq 

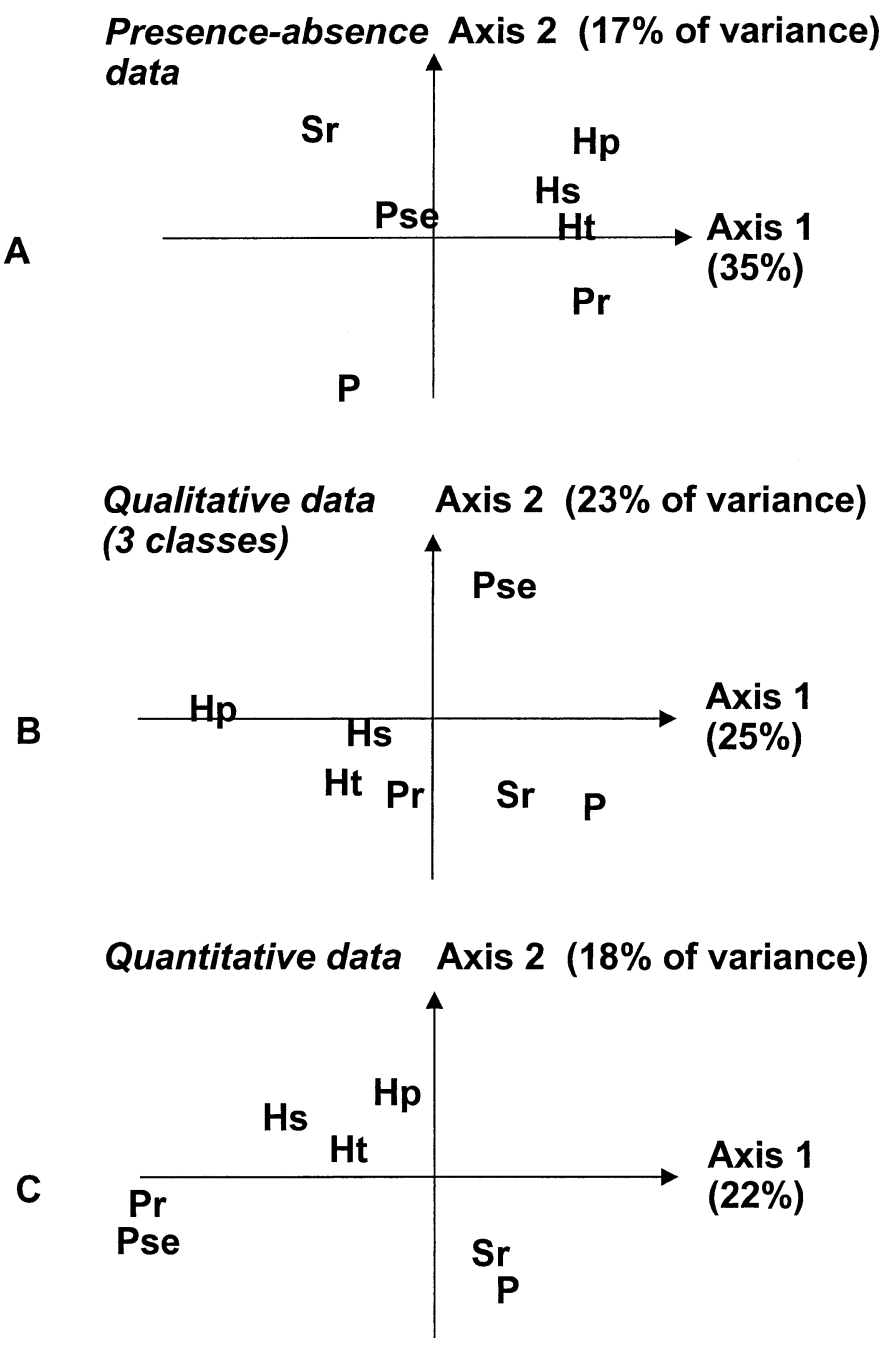

Figure 2. Associations between species using simple CA based either on presence-absence data (A) or abundance data divided into 3 classes (B) as in Fig. 1, or principal component analysis of abundance data (C). Cestodes: Hp (Hymenolepis pistillum), Hs ( $\mathrm{H}$. scalaris), $\mathrm{Ht}$ (H. tiara), and Pr (Pseudhymenolepis redonica). Nematodes: P (Porrocaecum sp), Pse (Pseudophysaloptera $\mathrm{sp}$ ), and $\mathrm{Sr}$ (Stammerinema rhopalocephala).

were of the same magnitude (Table II). However, these distances were slightly different when comparing the t2 set of distances obtained from Fig. 2A and B (Mantel test: $P=0.09$ ); the value $P>0.05$ indicates that differences are statistically significantly different, i.e., that the 2 sets of distances were not statistically related. The differences were related to the associations of $H$. pistillum with other cestodes (mean dCApa $=0.18$ and mean $\mathrm{dCAq}=0.36)$. A similar finding was observed for the associations of $P$. redonica with other cestodes (mean $\mathrm{d}$ CApa $=0.21$ and mean $\mathrm{dCAq}=0.51$ ). Thus, the distances were greater than expected from presence-absence data. These 2 cestodes were the most abundant species, which could indicate that abundance might interfere with the degree of positive associations. The dCAq values differed from the bivariate estimates (Mantel test: $P=0.15$ ), with $P>0.05$ indicating that the differences are statistically different. This suggests that spe- cies associations based on pairs of species or on all species associations could lead to slightly different interpretations when qualitative data divided into 3 classes of infection are examined.

\section{DISCUSSION}

Environment did not play a large role in the helminth fauna established in the C. russula from Albufera Park. This is possibly due to the uniformity of the environment at the scale investigated. Although biotopes B1 and B2 could be differentiated by the presence of birds (more numerous in B2), which are the definitive hosts for most of the nematodes found in $C$. russula, the B2 biotope did not contain many nematodes (Fig. 1). The fact that sampling areas within a given biotope did not affect assemblages of species is not surprising because the environment was very similar and shrew migrations occurred among these sampling areas (Favre et al., 1997). The presence or abundance of parasites was somewhat modified by the age or sex of the shrews but only to a limited extent. The role of host characteristics (age and sex) on parasite abundance and assemblage remained slight, as already shown in other hostparasite groups (Sasal et al., 1999) and accounted for 5-12\% of the variance in canonical analyses. Environment was not a decisive factor in determining the presence or absence of parasite species because the 2 axes in multiple CA accounted for only $18 \%$ of the variance. No correction for the environment was therefore necessary when investigating associations between species.

The relative abundance of a parasite species within a community may depend on density-dependent processes and interactions or on functional-ecological or phylogenetic constraints. Brooks (1980), Price (1987), and Rohde (1989) have suggested for a variety of reasons, e.g., history, turnover of parasites, and accumulation without saturation in host species, that parasite communities are noninteractive. Rohde et al. (1998) indicated that $70 \%$ of the studied parasite assemblages in fish were not interactive. The community organization of parasites has been identified as isolationist, i.e., independently distributed species have been identified (Kennedy et al. [1986] in fish and Goater et al. [1987] in salamanders) but also as interactive, where interaction plays a role in determining the structure of the community, i.e., Goater and Bush (1988) in birds, and Lotz and Font (1991), in bats. Pence (1990) described further the criteria for predicting an isolationist (noninteractive) community. There was a low probability of colonizing the host, direct life cycles, unsaturated niches, low species richness, and small number of high-density species. The helminth community of shrews was characterized by species with a low probability of colonizing the host (low prevalence) and low species richness ( 7 species), even if we only consider species with prevalence of more than $4.0 \%$, and small number of high-intensity species (H. pistillum and $P$. redonica). Presence-absence data (which are not much affected by density dependence) yield more similar association patterns (except in the case of $P$. redonica and Pseudohymenolepis sp.) than quantitative data (which are affected to a greater extent by density dependence). We may expect that density does not play an active role in association patterns, e.g., that niche use is not saturated. According to Pence (1990), this should be an isolationist community. We may thus view the shrew community, as proposed by Pence (1990), as being noninteractive 
(isolationist). Haukisalmi and Henttonen (1994), studying the habitat segregation of helminths in other species of shrews, noted the small size of helminths, their low degrees of aggregation in hosts, and large intestinal space, factors that could explain why regulatory effects due to space or niche are not important.

The major determinant of helminth assemblages in shrews is phylogenetic or functional. Nematodes, for example, engulf their food and are grouped together, as opposed to the cestodes, which are absorbers. The cestodes of $C$. russula thus constitute a guild because they are ecologically similar, especially in the way they use resources. They all live in the intestine, $C$. russula is their only definitive host, and they have indirect life cycles involving insects. They all belong to the Hymenolepididae and, therefore, are also phylogenetically closely related. The $\mathrm{Hy}$ menolepis spp. was always closely associated (Fig. 2A-C), whatever the analysis. Moreover, $P$. redonica was also more loosely associated with the Hymenolepis spp., suggesting that phylogenetic similarity was possibly an important determinant in structuring the assemblage of cestode species. The nematodes (ingestor guild) were conversely more diverse with respect to their life cycles (indirect, and in several species, the shrews were used as paratenic hosts), location in the host (stomach, intestine, abdominal or thoracic cavities), host specificity, and phylogeny (they belong to the Physalopteridae, Acuariidae, or Ascarididae). Among the 3 species of nematodes, Pseudophysaloptera sp., which has an indirect life cycle but does not use shrews as a paratenic host, is located in the stomach and is associated with both nematode and cestode species. Helminth species associations in shrews are apparently influenced mainly by phylogeny and only secondarily by life-cycle similarities.

\section{ACKNOWLEDGMENTS}

The study was supported in part by projects PB92-0517 and PB960401-C02-02 of the Dirección General de Investigación Cientifica y Técnica (DGICYT) of the Spanish Ministry of Education and Science. We gratefully acknowledge funding through an Erasmus scholarship from the European community to E.P. and of a short stay to J.C. in Valencia by the Faculty of Pharmacy of Valencia for data analyses. The field study was funded by the Spanish DGICYT and by the Ministry of Education and Science. Thanks are also due to J. C. Quentin (University of Orléans, France) for identification of several helminths and to F. Faus (Valencia) and A. Arrizabalaga (Museum of Granollers, Granollers) for the identification of hosts.

\section{LITERATURE CITED}

BARGER, I. A. 1984. Correlations between numbers of enteric nematode parasites in grazing lambs. International Journal for Parasitology 14: $587-589$.

BRooKs, D. R. 1980. Allopatric speciation and non-interactive parasite community structure. Systematic Zoology 30: 192-203.

CABARET, J., AND H. Hoste. 1998. Comparative analysis of two methods used to show interspecific associations in naturally acquired parasite nematode communities from the abomasum of ewes. Veterinary Parasitology 76: 275-285.

DicE, L. R. 1945. Measures of the amount of ecological association between species. Ecology 26: 297-302.

FAus, F. V. 1990. Los mamiferos de l'Albufera de Valencia: Datos preliminares. Medi Natural 2: 113-128.

Favre, L., F. Balloux, J. Goudet, and N. Perrin. 1997. Female-biased dispersal in the monogamous mammal Crocidura russula: Evidence from field data and microsatellite patterns. Proceedings of the Royal Society of London B Biological Sciences 264: 127-132.

Feliu, C., F. Renaud, F. Catzeflis, J. P. Hugot, P. Durand, and S. MORAND. 1997. A comparative analysis of parasite species richness of Iberian rodents. Parasitology 115: 453-466.
Goater, T. C., G. W. Esch, AND A. O. Bush. 1987. Helminth parasites of sympatric salamanders. Ecological concepts at infracommunity, component and compound community levels. American Midland Naturalist 118: $289-300$.

- AND A. O. BusH. 1988. Intestinal helminth communities in long-bill curlews: The importance of congeneric host-specialists. Holarctic Ecology 11: 140-145.

Haukisalmi, V., and H. HentTonen. 1994. Distribution patterns and microhabitat segregation in gastrointestinal helminths of Sorex shrews. Oecologia 97: 236-242.

Holmes, J. C., AND P. W. Price. 1986. Communities of parasites. In Community ecology: Pattern and process, D. J. Anderson and J. Kikkawa (eds.). Blackwell Scientific Publications, London, U.K., p. $187-213$.

JACCARD, P. 1908. Nouvelles recherches sur la distribution florale. Bulletin de la Société Vaudoise des Sciences Naturelles 44: 223-270.

Joyeux, Ch., AND J. G., BAER. 1936. Quelques helminthes nouveaux et peu connus de la musaraigne, Crocidura russula Herm. (Première partie, Trématodes et Cestodes). Revue Suisse de Zoologie 43: 25 50.

—, AND —. 1937. Quelques helminthes nouveaux et peu connus de la musaraigne, Crocidura russula Herm. (Deuxième partie, Nématodes et Acanthocéphales). Revue Suisse de Zoologie 44: 27 40.

Kennedy, C. R., A. O. Bush, And J. M. Aho. 1986. Patterns in helminth communities: Why are birds and fish different. Parasitology 93: 205-215.

LEGENDRE, L., AND P. LEGENDRE. 1979. Ecologie numérique. 2. La structure des données écologiques. Masson, Paris and Les Presses de l’Université du Québec, Montreal. 254 p.

LotZ, J. M., AND W. F. FonT. 1991. The role of positive and negative interspecific associations in the organization of communities of intestinal helminths of bats. Parasitology 103: 127-138.

, AND - 1994. Excess positive associations in communities of intestinal helminths of bats: A refined null hypothesis and a test of facilitation hypothesis. Journal of Parasitology 80: 398-413.

MANTEL, N. 1967. The detection of disease clustering and a generalized regression approach. Cancer Research 27: 209-220.

Mas-ComA, S. 1977. Contribución al conocimiento de la helminthofauna de micromammíferos iberícos. III Parásitos de Crocidura russula Hermann, 1780 (Insectivora: Soricidae). Säugertierkundliche Mitteilungen 25: 67-78.

, AND C. FELIU. 1977. Helmintofauna de micromamíferos de las Islas Medas (Cataluña, España). Vie et Milieu 27: 231-241.

- AND J. Gallego. 1975. Contribución al conocimiento de la helmintofauna de micromammíferos ibéricos. I. Parásitos de Sorex spp. (Insectivora: Soricidae). Revista Ibérica de Parasitología 35: 261-281.

— AND —. 1977. Conocimientos actuales sobre la helmintofauna de micromamíferos (Insectivora; Rodentia) en España. In Indice-Catálogo de Zooparásitos Ibéricos. III. Cestodos. IV. Nematodos y Anejos, M. Cordero del Campillo, and A. M. Fernandez (eds.). Gráficas Summa, Oviedo-León, Spain, p. 165-205.

Pence, D. B. 1990. Helminth community of mammalian hosts: Concepts at the infracommunity, component and compound community levels. In Parasite communities: Patterns and processes, G. W. Esch, A. O. Bush, and J. M. Aho (eds.). Chapman and Hall, London, U.K., p. 233-260.

Portoles, E., P. Granel, and J. G. Esteban. 1996. Helminthofaunistic analysis of Crocidura russula (Hermann, 1780) (Insectivora: Soricidae) from the Albufera natural Park (Valencia, Spain). Research and Reviews in Parasitology 56: 203-211.

Poulin, R., AND J. F. GuEgan. 2000. Nestedness, anti nestedness, and the relationship between prevalence and intensity in ectoparasite assemblages of marine fish. A spatial mode of species coexistence. International Journal for Parasitology 30: 1147-1152.

PRICE, P. W. 1987. Evolution in parasite communities. International Journal for Parasitology 17: 203-208.

Quentin, J. C. 1986. Nématodes parasites de musareignes en Sologne. Symbioses 18: 265-279.

RoHDE, K. 1989. Simple ecological systems, simple solutions to complex problems? Evolutionary Theory 8: 305-350.

, W. B. Worthen, M. Heap, B. Hugueny, and J. F. Guegan. 
1998. Nestedness in assemblages of metazoan ecto- and endoparasites of marine fish. International Journal for Parasitology 28: 543-549.

Root, R. B. 1967. The niche exploitation pattern of the blue-greengnat catcher. Ecological Monographies 37: 317-350.

Sasal, P., N. Niquil, AND P. BARTOli. 1999. Community structure of digenean parasites of sparid and labrid fishes of the Mediterranean Sea: a new approach. Parasitology 119: 635-648.

SoKAL, R., AND C. D. Michener. 1958. A statistical method for evaluating systematic relationships. University Kansas Scientific Bulletin 38: $1409-1438$.
STAT-ITCF. 1988. Manuel d'utilisation. Institut des Céréales et des Fourrages, Paris, France, 238 p.

Toledo, R., C. Muñoz-Antoli, M. Perez, and J. G. Esteban. 1998. Larval trematode infections in freshwater gastropods from the Albufera Natural Park in Spain. Journal of Helminthology 72: 7982.

VAuCHER, C. 1971. Les Cestodes parasites des Soricidae d'Europe. Etude anatomique, révision taxonomique et biologie. Revue Suisse de Zoologie 78: 1-113.

VESMANIS, I. E., AND A. VESMANIS. 1979. Ein Vorschlag zur eintheitlichen Altersabsttufug bei Winterspitzmäusen (Mammalia: Insectivora: Crocidura). Bonn Zoologische Beitrag 30: 7-13. 